\title{
Topoisomerase II alpha gene copy loss has adverse prognostic significance in ERBB2-amplified breast cancer: a retrospective study of paraffin-embedded tumor specimens and medical charts Lydia Usha*1, Bita Tabesh1, Larry E Morrison², Ruta D Rao1, Kris Jacobson², April Zhu ${ }^{3}$, Sanjib Basu ${ }^{4}$ and John S Coon ${ }^{5}$
}

\author{
Address: ${ }^{1}$ Division of Hematology and Oncology, Department of Medicine, Rush University; Chicago, Illinois, 60612, USA, ${ }^{2} \mathrm{Abbott}$ Molecular \\ Inc. Des Plaines, Illinois, USA, ${ }^{3}$ Midwest Palliative and Hospice Care Center, Glenview, Illinois, USA, ${ }^{4}$ Division of Statistics, Northern Illinois \\ University, De Kalb, Illinois, USA and ${ }^{5}$ Department of Pathology, Rush University; Chicago, Illinois, 60612, USA \\ Email: Lydia Usha* - lydia_usha@rush.edu; Bita Tabesh - bitatabesh@hotmail.com; Larry E Morrison - larry.morrison@abbott.com; \\ Ruta D Rao - ruta_rao@rush.edu; Kris Jacobson - kris.jacobson@abbott.com; April Zhu - azhu@carecenter.org; \\ Sanjib Basu - sanjib_basu@rush.edu; John S Coon - john_coon@rush.edu \\ * Corresponding author
}

Published: 14 August 2008

Journal of Hematology \& Oncology 2008, I:I2 doi:10.1 I86/I756-8722-I-I2

This article is available from: http://www.jhoonline.org/content/l/I//2

(c) 2008 Usha et al; licensee BioMed Central Ltd.

This is an Open Access article distributed under the terms of the Creative Commons Attribution License (http://creativecommons.org/licenses/by/2.0), which permits unrestricted use, distribution, and reproduction in any medium, provided the original work is properly cited.
Received: 16 June 2008

Accepted: 14 August 2008

\begin{abstract}
Background: Amplification of the ERBB2 (Her-2/neu) oncogene, which occurs in approximately $25 \%$ of breast carcinomas, is a known negative prognostic factor. Available data indicate that a variable number of nearby genes on chromosome $17 \mathrm{q}$ may be co-amplified or deleted, forming a continuous amplicon of variable size. In approximately $25 \%$ of these patients, the amplicon extends to the gene for topoisomerase II alpha (TOP2A), a target for anthracyclines. We sought to understand the significance of these associated genomic changes for breast cancer prognosis and predicting response to therapy.
\end{abstract}

Methods and patients: Archival tissue samples from 63 breast cancer patients with ERBB2 amplification, stages 0-IV, were previously analyzed with FISH probes for genes located near ERBB2. In the present study, the clinical outcome data were determined for all patients presenting at stages I-III for whom adequate clinical follow up was available.

Results: Four amplicon patterns (Classes) were identified. These were significantly associated with the clinical outcome, specifically, recurrence of breast cancer. The Amplicon class IV with deleted TOP2A had 67\% (6/9) cases with recurrence, whereas the other three classes combined had only $12 \%(3 / 25)$ cases $(p$-value $=0.004)$ at the time of last follow-up. TOP2A deletion was also significantly associated with time to recurrence $(p$-value $=0.0002)$. After adjusting for age in Cox regression analysis, the association between TOP2A deletion and time to recurrence remains strongly significant $(\mathrm{p}$-value $=0.002)$ whereas the association with survival is marginally significant ( $\mathrm{p}$-value $=0.06)$.

Conclusion: TOP2A deletion is associated with poor prognosis in ERBB2-amplified breast carcinomas. Clarification of the mechanism of this association will require additional study. 


\section{Background}

The ERBB2 (Her-2/neu) oncogene is amplified and overexpressed in $25 \%$ of invasive breast carcinomas [1-4]. In general, ERBB2 amplification confers an unfavorable prognosis, although its significance is less than that of the traditional prognostic factors - stage and grade. Also, it seems that the prognosis and response to therapy varies considerably within the spectrum of ERBB2-amplified breast carcinomas (BC), indicating that they are biologically heterogeneous. The first targeted anti-neoplastic agent, Trastuzumab (Herceptin ${ }^{\odot}$ ), a monoclonal antibody to ERBB2, produces a response in approximately $15 \%$ of heavily pretreated patients with metastatic $\mathrm{BC}$ as a single agent [5] and in combination with chemotherapy improved the overall survival of patients with metastatic BC by 5 months [6]. It has recently been shown to decrease the risk of $\mathrm{BC}$ recurrence by about $50 \%$ in patients with ERBB2 amplified tumors in the adjuvant setting [7]. Unfortunately, only a fraction of patients with ERBB2-amplified breast carcinomas respond to Trastuzumab, further evidence for heterogeneity among these tumors.

The ERBB2 oncogene is located at the $17 \mathrm{q} 12$ chromosomal locus. Many genes located close to ERBB2 on 17 q12-q21 are known or suspected to play a role in carcinogenesis, and specifically, in breast carcinogenesis. Previous studies demonstrated that the negative effect on the prognosis of BC attributed to ERBB2 amplification could, in fact, be due to co-amplification of the region adjacent but telomeric to ERBB2 [8]. One of the genes located in this region is Topoisomerase IIA (TOP2A). It has been demonstrated that amplification of ERBB2 in BC cell lines and in primary breast tumors is associated with simultaneous amplification or deletion of the TOP2A gene [9-14]. Also, it has been shown that in $\mathrm{BC}$, amplification of ERBB2 correlates with overexpression of TOP2A [15], but it cannot predict it [11]. Some authors argue that ERBB2 and TOP2A overexpression could be independent prognostic factors of poor survival in BC [16].

Topoisomerases are nuclear enzymes that modulate the topology of DNA by modifying the tertiary structure of the double helix. TOP2A is a $170-\mathrm{kD}$ protein that binds to DNA, forming the cleavable complex, which allows intertwined replicated DNA strands to physically separate at the end of mitosis [17]. TOP2A is more highly expressed in rapidly proliferating cells, and expression is limited to the $\mathrm{S}$ to G2/M phases of cell cycle. TOP2A is a molecular target for some important anticancer drugs, including anthracyclines, which are the key chemotherapeutic agents in the treatment of $\mathrm{BC}$. Anthracyclines stabilize the TOP2A cleavable complex and inhibit TOP2A catalytic activity (ibid). Therefore, it has been suggested that the empiric observation that ERBB2-amplified BCs respond relatively well to anthracycline-based chemotherapy [1823 ] is due to co-amplification of TOP2A [24-28]. These data suggest that co-amplification of at least one of the genes adjacent to ERBB2 can play a role in the response to a specific chemotherapeutic agent widely used in the treatment of BC. The significance of amplification or deletion of other genes adjacent to ERBB2 remains to be determined. TOP2A aberrations (amplification or deletions) occur in less than $10 \%$ of ERBB2 non-amplified breast tumors [29]. This indicates that ERBB2 amplification could be the primary genetic event involving chromosome $17 \mathrm{q}$ in breast carcinogenesis and the TOP2A alterations are secondary events.

We showed previously that amplification of ERBB2 and nearby genes appears to form a single amplicon of variable size, without intervening normal or deleted segments [30], consistent with the break-fusion-bridge model for gene amplification [30,31], where recurrent doublestranded DNA breaks occur at vulnerable sites which become starting points for further amplifications or telomeric deletions. We systematically analyzed the amplification patterns of the region telomeric to ERBB2, using a series of fluorescence in-situ hybridization (FISH) probe sets. We determined that there are significant variations of the amplicon size, and that TOP $2 A$ can be amplified, normal or deleted. Here we conducted a retrospective study to determine whether the amplicon pattern, including amplification or deletion of TOP $2 A$ correlates with clinico-pathologic characteristics of breast tumors, markers of proliferation, and the clinical outcome of patients with ERBB2-amplified BC.

\section{Results \\ Chromosome I7q gene copy abnormality patterns in ERBB2-amplified BCs}

We showed previously that BCs with ERBB2 amplification have variable amplification and deletion of genes telomeric to ERBB2 [30]. This was demonstrated with the Vysis ERBB2 probe and 7 other FISH probes covering an adjacent $889 \mathrm{~kb}$ telomeric region (Figure 1). The amplified region (amplicon) may extend to or even beyond the TOP2A gene, contained within the $291 F, 291 Z .6,291 Z .2$ probes, and appears to be continuous in $90 \%$ of cases studied, without intervening regions of normal copy number or deletion. If deleted segments are present, they begin just telomeric to the amplified segment, and almost always involve the TOP2A gene. In this study, the status of the $291 Z .2$ probe was used to assess the copy number of the TOP2A gene because: 1 ) the gene is more centrally located within the $291 Z .2$ sequence, as opposed to the $291 \mathrm{~F}$ probe for which TOP $2 A$ is located near its telomeric end (furthest from ERRB2), and 2) 291Z.2 targets a larger region than $291 Z .6$, thereby providing a brighter signal that would be more accurately visualized in poorer quality 


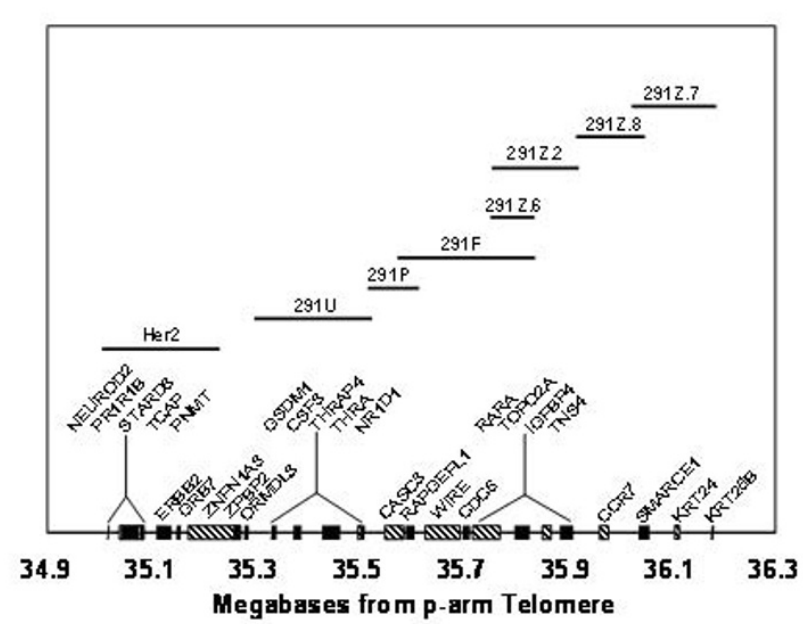

Figure I

Diagram showing location of FISH probes and selected genes on chromosome I7. The locations of the 6 mapping probes and $\mathrm{LSI}^{\circledR}$ Her2 probe pictured in Figure I are based on the probe sequences in the May 2006 assembly of the human genome browser on the University of California, Santa Clara web site http://genome.ucsc.edu/.

specimens. The disadvantage of the TOP2A sequence lying near the terminus furthest from $E R B B 2$ in the $291 \mathrm{~F}$ targeted region is that amplicons can terminate just centromeric to TOP $2 A$ but still contain the majority of the $291 \mathrm{~F}$ sequence, producing $291 \mathrm{~F}$ signals bright enough to be counted as amplified, and misrepresenting the TOP $2 \mathrm{~A}$ gene status.
Here, we have classified the $17 \mathrm{q}$ gene copy abnormalities of 63 BC, including 9 cases with only DCIS, all with amplification of ERBB2 by FISH, into 4 categories of similar frequency, to permit comparison with other tumor attributes and clinical outcome:

Class I: ERBB2 and TOP2A both amplified (25.4\% of total);

Class II: Only ERBB2 amplified (no other mapping probe loci amplified), TOP2A normal (23.8\% of total),

Class III: ERBB2 and neighboring mapping loci amplified, TOP $2 A$ normal (25.4\% of total),

Class IV: ERBB2 amplified but TOP2A deleted (25.4\% of total).

\section{Associations between Amplicon Class, clinical and pathologic characteristics of breast tumors}

Tests for association of Amplicon Class and accepted descriptors of breast carcinoma for all 63 patients are summarized in Table 1. No significant associations between Amplicon Class and presence of invasion, histological type, grade, stage, patient age, or hormone receptor status were found.

\section{Associations between TOP2A gene copy number, protein expression, and cell proliferation}

We studied nuclear TOP2A expression by immunohistochemistry (IHC) to determine whether it paralleled the gene copy (FISH) studies. A comparison of the frequency of expression by tumor cell nuclei versus Amplicon Class did not show a significant association $(\mathrm{p}=0.50)$, data not

Table I: Clinical and pathologic characteristics of breast tumors by Amplicon class

\begin{tabular}{|c|c|c|c|c|c|c|}
\hline \multirow[t]{2}{*}{ Tumor Properties } & & \multicolumn{5}{|c|}{ Amplicon Class, number of patients } \\
\hline & & Class I & Class II & Class III & Class IV & p-value \\
\hline \multirow[t]{2}{*}{ Invasion } & present & 14 & 12 & 14 & 14 & 0.913 \\
\hline & DCIS only & 2 & 3 & 2 & 2 & \\
\hline \multirow[t]{2}{*}{ Type (invasive) } & Ductal & 12 & 12 & 14 & 14 & 0.115 \\
\hline & Lobular & 2 & 0 & 0 & 0 & \\
\hline \multirow[t]{2}{*}{ Grade (invasive) } & II & 5 & 2 & 1 & 4 & 0.146 \\
\hline & III & 9 & 10 & 13 & 10 & \\
\hline \multirow[t]{4}{*}{ Clinical Stage } & 1 & 5 & 6 & 6 & 4 & 0.336 \\
\hline & II & 4 & 5 & 5 & 5 & \\
\hline & III & 2 & 2 & I & 5 & \\
\hline & IV & 3 & 0 & I & 0 & \\
\hline \multirow[t]{2}{*}{ Age } & under 50 & 6 & 6 & 7 & 9 & 0.720 \\
\hline & over 50 & 10 & 9 & 9 & 7 & \\
\hline \multirow[t]{4}{*}{ Hormone receptors } & $\mathrm{ER}+/ \mathrm{PR}+$ & 4 & 3 & 3 & 3 & 0.710 \\
\hline & $E R+/ P R-$ & 4 & 2 & 5 & 3 & \\
\hline & ER-/PR+ & 2 & 1 & 0 & 0 & \\
\hline & ER-/Pr- & 4 & 6 & 6 & 8 & \\
\hline
\end{tabular}


shown. Similarly, comparing TOP2A expression frequency versus the TOP $2 A$ gene categorized as amplified, normal or deleted, did not show a significant association $(\mathrm{p}=0.38)$, data not shown.

TOP2A expression level has been reported to reflect the proliferation rate of tumors [17], and some authors have suggested that associations between TOP2A expression and/or gene amplification and the biological behavior of tumors occur on this basis (ibid). Here, we observed that TOP2A expression did show a modest association with expression of MIB1, a standard IHC assay for cell proliferation, correlation coefficient 0.54 (Figure 2).

The presence or absence of TOP2A amplification was not associated with the frequency of MIB1 expression ( $\mathrm{p}=$ 0.79), nor was Amplicon Class associated with MIB1 frequency $(\mathrm{p}=0.58)$.

\section{Association of BC clinical outcome with Amplicon Class and TOP2A gene copy number}

The analysis of the clinical outcome data by chart review were obtained for 34 patients who presented with Stage IIII invasive $\mathrm{BC}$ and who had at least 18 months of clinical follow-up. The 9 patients with only DCIS were excluded from this analysis. Twenty-one other patients were also excluded, most often because follow-up was unobtainable, or they presented with Stage IV disease. Twenty patients received anthracycline-based therapy in the adjuvant setting and 3 in the neoadjuvant setting. The remainder never received anthracycline therapy, Table 2

The Amplicon Class IV, with TOP2A deletion, had 67\% $(6 / 9)$ cases with unfavorable outcome, whereas the other

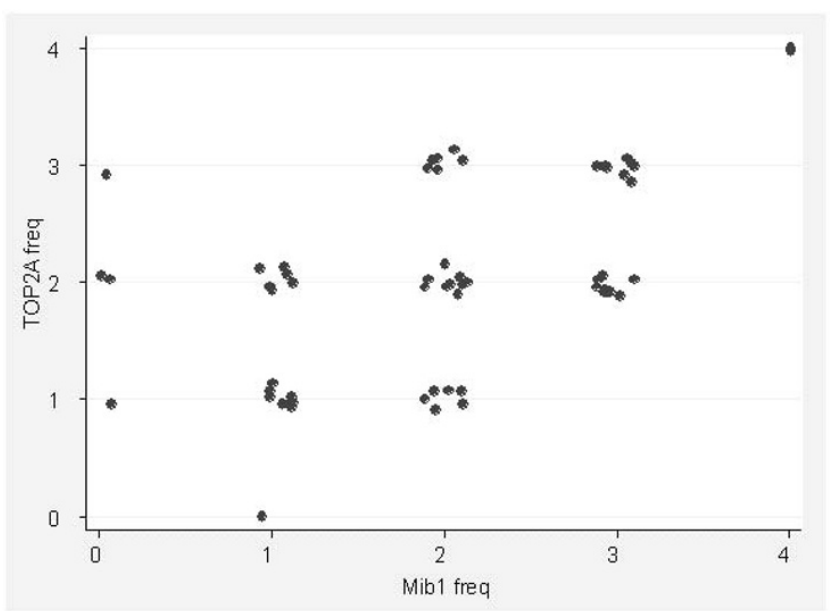

\section{Figure 2}

Association between frequency of expression of TOP2A and MIBI in breast carcinoma cells. three classes combined had only 12\% (3/25) unfavorable outcomes. The association of TOP $2 A$ deletion with unfavorable outcome was strongly significant ( $\mathrm{p}$ value $=0.004$ from Fisher's exact test), whereas TOP $2 A$ amplification (Class I) did not confer a better outcome than normal TOP2A copy number (Class II and III). In contrast, no association was found between clinical outcome categories and expression of TOP2A $(\mathrm{p}=0.66)$ or expression of MIB1 ( $\mathrm{p}=0.695)$. Clinical outcome categories were also not associated with tumor grade $(\mathrm{p}=0.69)$, stage $(\mathrm{p}=$ $0.25)$, ER status $(\mathrm{p}=0.78)$, PR status $(\mathrm{p}=0.54$, or patient age $(p=0.78)$. Five of the 9 unfavorable outcomes occurred in patients who had never received anthracycline therapy.

The Kaplan-Meier estimates of time to tumor recurrence for patients with TOP $2 A$ deletion versus others are shown (Figure 3). 56\% of cases are estimated to recur by 18 months in the TOP $2 A$ deleted group, whereas only $8 \%$ are estimated to recur in the other patients. The difference in time to recurrence between these two groups is strongly statistically significant ( $\mathrm{p}$-value $=0.0002$ from a log-rank test). Since the sample sizes are small, we also obtained the permutations based p-value of the log-rank test using the ExactRankTests package of the R statistical software, this latter $\mathrm{p}$-value $=0.0006$.

The Kaplan-Meier survival estimates of the TOP2A deletion group versus others are shown in Fig 4 (Figure 4). $44 \%$ (4/9) patients died during the follow-up in the TOP $2 A$ deletion group whereas $12 \%(3 / 25)$ died in the other group. The difference in survival between these two groups is statistically significant ( $\mathrm{p}$-value $=0.04$ from a log-rank test and $=0.03$ from the exact permutation based approach).

Due to the limited sample size, we considered multivariate analysis with TOP2A deletion and one additional covariate at a time. TOP $2 A$ deletion had significantly increased hazard of recurrence $(\mathrm{HR}=8.6, \mathrm{p}$-value $=0.002)$ than the other group in a Cox proportional hazards regression analysis which also included age as a covariate. TOP2A deletion also had significantly increased hazard of recurrence after adjustment by grade $(\mathrm{HR}=9.5, \mathrm{p}$-value $=$ 0.002 ) and after adjustment by ER status (HR = 9.2, pvalue $=0.002)$. The effect of TOP2A deletion on survival was marginally significant $(\mathrm{HR}=5.2, \mathrm{p}$-value $=0.06)$ after adjustment by age. The effect of age, grade and ER were not at all significant in either one of these analyses.

Thus, we found that Amplicon Class with TOP2A deletion in ERBB2-amplified $\mathrm{BC}$ was associated with shorter time to tumor recurrence and significantly higher risk of cancer recurrence independent of other covariates. 
Table 2: Clinical outcome is associated with Amplicon Class for patients with stage I-III invasive breast cancer

\begin{tabular}{lll}
\hline Amplicon Class & & Clinical outcome and number of patients (Total N = 33) \\
\cline { 2 - 3 } & NED or DNED & AWD or DOD \\
\hline Class I & $6(4)$ & $2(0)$ \\
Class II & $6(5)$ & $1(0)$ \\
Class III & $9(9)$ & 0 \\
Class IV & $3(1)$ & $6(4)$ \\
\hline
\end{tabular}

NED: alive with no evidence of disease. DNED: died with no evidence of disease at least 24 months after diagnosis. AWD: Alive with breast cancer. DOD: died of breast cancer. NED and DNED were categorized as favorable outcome, and DOD and AWD as unfavorable for this analysis. Numbers in parentheses refer to the number of patients who received anthracycline-based therapy. The association between Amplicon class and clinical outcome is strongly significant, permutation based exact $p$-value $=0.007$ from a chi-square test.

\section{Discussion}

This paper is the first attempt to relate the characteristics of the highly variable ERBB2-TOP2A amplicon in BC, categorized into clearly defined Amplicon Classes, to the phenotype of the tumors. The Amplicon Classes were not associated with the commonly used descriptors of breast neoplasia. Specifically there was no evidence that Amplicon Class was associated with the ability of tumor cells to invade normal tissue, since the Class distribution was similar in invasive carcinoma and DCIS. Amplicon Class also seemed not to vary with stage at presentation, or hormone receptor status. These observations suggest that Amplicon Class may be independent of the most useful classical prognostic markers.

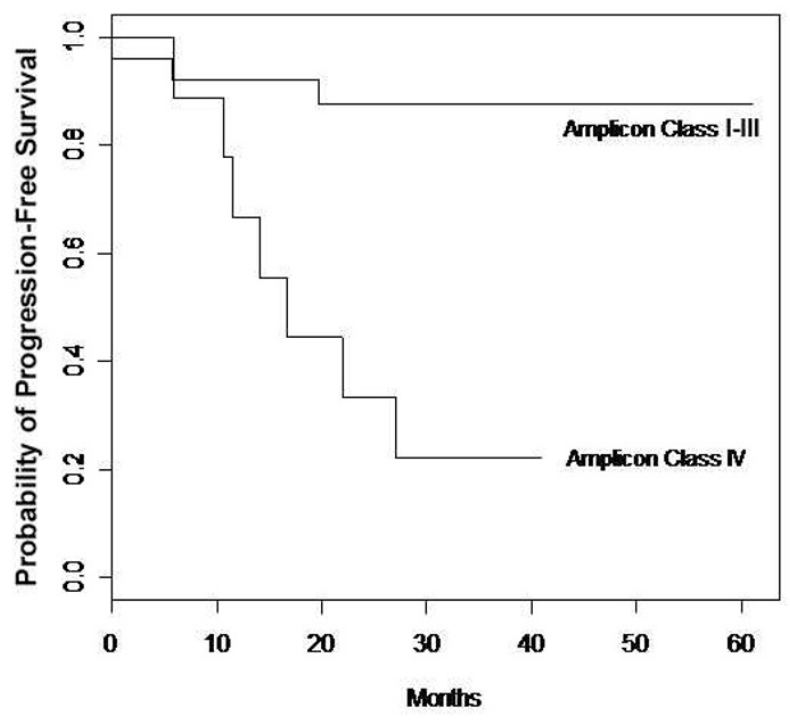

Figure 3

Time to recurrence for patients with stage I-III invasive breast cancer by Amplicon Class.
TOP2A deletion emerged as a strong predictor of unfavorable outcome and shorter disease-free survival, whereas no significant association with TOP2A amplification was found. This is not inconsistent with our previous study of local tumor response in locally advanced BC, most of which did not have ERBB2 amplification, and all of which were treated with neoadjuvant anthracycline-based therapy [25]. TOP2A amplification was associated with tumor response in this study, but the patients and the end point were quite different than the present study. Comparing Amplicon Class II with Amplicon Class III, amplification of genes between ERBB2 and TOP2A was also not associated with outcome or time to recurrence in this study. We also assessed TOP2A expression by IHC, but we did not find a significant association with clinical outcome or

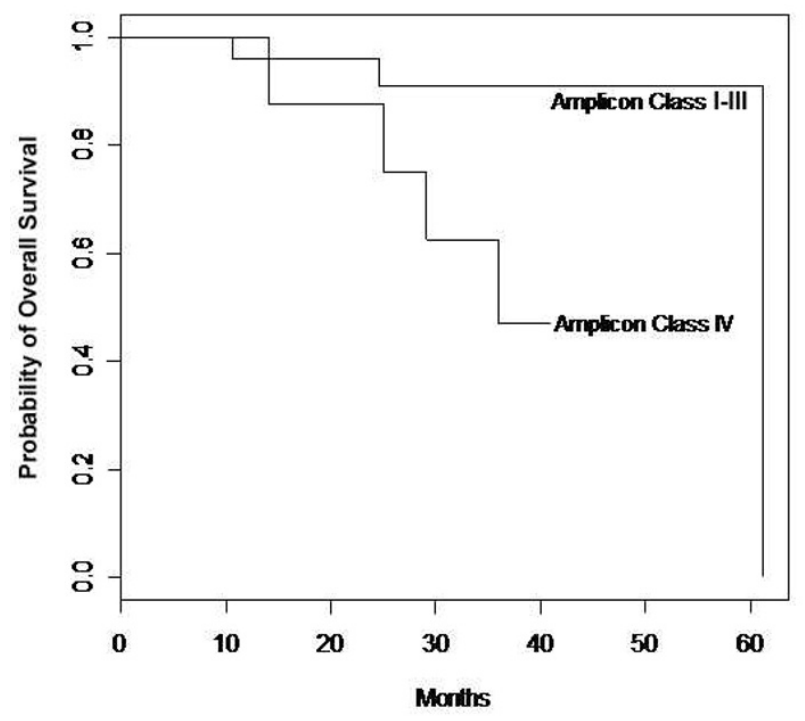

Figure 4

Survival for patients with stage I-III invasive breast cancer by Amplicon Class. 
time to recurrence. TOP $2 A$ deletion was not associated with significantly reduced expression of TOP2A. This raises the possibility that TOP $2 A$ deletion may be a marker for another genetic event, most likely involving a nearby gene, whose altered expression confers an adverse prognosis. In fact, the 291Z.2 probe contains all or part of at least 3 genes in addition to TOP2A (Figure 1). Identifying the significant gene will require studying more patients with TOP2A deletion at higher resolution. It is not possible to link the adverse prognostic significance of TOP $2 A$ deletion to anthracycline resistance in this group of patients, since 5 of the 9 patients with adverse outcomes did not receive anthracyclines. Given the existing evidence on the higher likelihood of TOP2A amplified tumors to respond to anthracyclines, this observation may indicate that TOP2A deletion is an unfavorable prognostic marker independent of chemotherapy, but the small number of patients does not allow drawing any definitive conclusion. The association between clinical outcome and anthracycline therapy (received vs. not received) was not significant ( $\mathrm{p}=0.4$ from Fisher's exact test).

This study of Amplicon Class versus clinical outcome is based upon a small number of highly selected (ERBB2amplified) BC patients with relatively short follow-up. These factors probably account for several unexpected findings in this study. Among all factors considered only TOP2A deletion was associated with survival. We have not observed the correlation between survival and stage, presumably because the follow-up was too short. The fact that all of the tumors had ERBB2 amplification may have obscured the association of other established prognostic factors, such as ER and PR with outcome. Nevertheless, the study is significant because it demonstrates that the recently recognized molecular heterogeneity of the ERBB2 amplification event may have clinical significance, although this finding requires confirmation in a larger group of patients. It has been assumed that the adverse effect of ERBB2 amplification is mediated largely or entirely via associated overexpression of the ERBB2 oncogene, but associated copy abnormalities in nearby genes may also be involved [32].

TOP2A has been studied in BC by other investigators, primarily because it is a marker of proliferation and a target for anthracyclines [33-35]. However, the information on the prognostic role of TOP2A is limited and the use of anthracyclines could be a confounding factor to assess it. Moreover, in previous studies [15,36] the prognostic role of TOP2A in BC was frequently studied by correlating its expression by IHC with the clinical outcome. More recent studies showed that TOP2A expression measured by is cell cycle-dependent and thus, indicates the number of proliferating cells rather than nuclear TOP $2 A$ status in a given tissue. Furthermore, cell proliferation potentially can be a source of bias in measuring TOP2A protein [37]. Since anthracyclines interact with TOP2A in the nucleus, it is important to determine TOP2A expression in the nucleus which can be done most accurately by determining TOP2A copy number as a surrogate marker. To illustrate this point Burgess et al. utilized RNA interference to knockdown TOP2A gene in the nucleus of lymphoma cells which resulted in increased resistance to an anthracycline, doxorubicin, but has not affected cell proliferation [28]. Our results confirmed that TOP2A expression in BC cells by IHC is associated with proliferation (MIB-1), but neither marker was associated with outcome in this group of patients. The association between TOP $2 A$ deletion and adverse outcome in these patients appears, therefore, to be unrelated to the cell proliferation rate.

A number of retrospective analyses of tissue specimens from earlier adjuvant clinical trials with anthracycline and non-anthracycline chemotherapy regimens have been recently published $[9,19,27,38,39]$. The body of literature supports the idea that TOP2A status predicts the response to anthracyclines in $\mathrm{BC}$ and it is possible that clinical benefit from anthracyclines is limited to patients with ERBB2 and TOP2A amplified tumors. However, the prognostic and predictive value of TOP $2 A$ deletion remains controversial. The occurrence of TOP2A deletion in $\mathrm{BC}$ has been well documented previously, primarily in tumors with ERBB2 amplification $[31,37,40,41]$. In the study of Hicks et al. [29] 50\% of ERBB2-amplified breast tumors had TOP2A co-amplification and $16 \%$ had monoallelic deletion of TOP2A. In ERBB2 non-amplifed tumors, TOP2A was never amplified and in 5\% of the tumors there were monoallelic deletions of both ERBB2 and TOP2A genes (ibid). In one published analysis of a large collection of primary breast tumor samples, TOP $2 A$ alterations were reported in $23 \%$ of all tumors, regardless of their ERBB2 status: $12 \%$ had TOP $2 A$ amplification and $11 \%$ had TOP2A deletion [38]. In this study both TOP $2 A$ amplification and deletion were associated with improved recurrence-free and overall survival if treated with anthracycline-based chemotherapy as opposed to a nonanthracycline regimen.

Our data confirm the results of the recently published retrospective analysis of tissue samples from the large adjuvant clinical trial [42] which have demonstrated that TOP2A aberrations, including both TOP $2 A$ amplifications and deletions, are significantly associated with shorter recurrence free and overall survival. A clear benefit from adjuvant anthracyclines was identified in women with TOP2A amplifications $[38,29,42]$ and a non-significant trend for improved survival was observed in women with TOP2A deletions [42]. Thus, the TOP2A deletion in BC seems to confer a poor prognosis, but more studies are 
needed to elucidate the responsiveness of these tumors to anthracyclines.

Trastuzumab may be synergistic, additive or antagonistic in combinations with different chemotherapeutic agents. With the recent approval of Trastuzumab for the adjuvant treatment of $\mathrm{BC}$ and expanding its use, the importance of exploring molecular markers in the vicinity of ERBB2 is increased [43,44]. Slamon et al. [1] recently illustrated this point with the preliminary analysis of the BCIRG 006 clinical trial data [45]. These results suggest that patients with co-amplification of TOP2A comprise the subset of patients who benefit from anthracyclines in the adjuvant setting. Therefore, patients without TOP2A co-amplification may be better treated with combinations of nonanthracycline drugs with Trastuzumab, which would decrease the risk of cardiotoxicity. In fact, we recently reported that $E R B B 2$ amplicons that did not extend to the 291Z.2 (TOP2A) locus (Class II + Class III amplicons) were associated with improved response to trastuzumab relative to amplicons that included the 291Z.2 locus (Class I amplicons) [46]. Although the combination of Trastuzumab and anthracyclines may seem to be very powerful against ERBB2 and TOP2A amplified $\mathrm{BC}$, this combination is cardiotoxic. It would seem reasonable to search for new non-cardiotoxic inhibitors of TOP2A to combine with Trastuzumab. One of these agents, suberoylanilide hydroxamic acid (SAHA), is currently in clinical trials $[47,48]$.

\section{Conclusion}

The TOP2A deletion is associated with increased risk of $B C$ recurrence and death from breast cancer in patient with ERBB2 amplified BC. Clarification of the mechanism of this association will require additional study.

\section{Materials and methods Hybridization Probes}

The probes have been described in detail previously [30]. Single clones used for FISH probes were the following: 291U (RP11 BAC 283i23), 291P (RP5 PAC 1152A16), 291F (CITB BAC 428H21), 291Z.2 (RP11 BAC 5809), 291Z.6 (Genome Systems P1 \# 611), 291Z.7 (RP11 BAC 89A22), and 291Z.8 (RP1 PAC 1028K7). The single clones lie within a contig beginning about $69 \mathrm{~kb}$ telomeric of the Vysis LSI ${ }^{\circledast} H E R-2$ probe and extending for approximately $889 \mathrm{~kb}$ toward the $17 \mathrm{q}$ telomere (see Figure 1) Each in situ hybridization included 3 FISH probes directly labeled with different fluorophores: a peri-centromeric alpha satellite probe for chromosome 17 (Vysis $^{\circledast}$ SpectrumAqua $^{\mathrm{TM}}$ $\mathrm{CEP}^{\circledast}$ 17; Abbott Molecular Inc, Des Plaines, IL), a probe for ERBB2 (Vysis SpectrumGreen ${ }^{\mathrm{TM}}$ LSI $^{\circledast}$ HER-2, Abbott Molecular) and one of 7 single-clone probes telomeric to $E R B B 2$ labeled with SpectrumOrange ${ }^{\mathrm{Tm}}$.

\section{Specimens}

Fifty-four specimens from patients with invasive BC and 9 patients with ductal carcinoma in situ, without documented coexisting invasion, were obtained from the archives of the Pathology Department at Rush University Medical Center (Chicago, IL). They comprised left-over diagnostic material from patients seen between 1998 and 2003. There was sufficient archival material available for all of the patients included to ensure that the study did not exhaust the diagnostic tumor tissue. ERBB2 amplification was verified for all patients as part of this study, by use of the PathVysion ${ }^{\circledast}$ FISH panel (Abbott Molecular). Paraffin blocks were sectioned at $5 \mu \mathrm{m}$ thickness and mounted onto SuperFrost Plus ${ }^{\circledast}$ positively charged slides (ThermoShandon, Pittsburgh, PA).

\section{Patients}

Patients with ERBB2-amplified BC treated at Rush University Medical Center, Chicago, Illinois, between 1997 and 2004 were considered for the study. The study was approved by the Rush Institutional Review Board. Only patients for whom adequate archival pre-therapy tumor tissue and adequate clinical follow-up data were available were eligible for the study. The median follow up for the patients in this study was 31 months. The diagnosis of invasive $\mathrm{BC}$ in the archival material was confirmed by histological evaluation before further analysis. The clinical outcome data was obtained by chart review. No patients in this study received adjuvant Trastuzumab because they were treated before the approval of Trastuzumab for the adjuvant treatment of BC.

\section{In Situ Hybridization}

The procedure has been described in detail previously [30]. Briefly, the specimens were prepared by immersion of the slides in Vysis Pretreatment Solution (Abbott Molecular) at $80^{\circ} \mathrm{C}$ for 10 minutes. The slides were then immersed in a solution of $4 \mathrm{mg}$ pepsin (2500-3000 U/ $\mathrm{mg}$ ), rinsed in water, and dehydrated in $70 \%, 85 \%$, and $100 \%$ ethanol. The slides were hybridized with the $3-$ color FISH probe solutions in a HYBrite ${ }^{\mathrm{TM}}$ automated COdenaturation oven (Abbott Molecular) and then immersed in $73^{\circ} \mathrm{C} 2 \times \mathrm{SSC} / 0.3 \% \mathrm{NP} 40$ for 2 minutes for removal of nonspecifically bound probe.

\section{Enumeration of FISH signals}

Typically, 30-90 cells were enumerated in each specimen. The FISH slides were evaluated under a Zeiss Axioscope epi-fluorescence microscope (Carl Zeiss, Thornwood, NY). Only nuclei with morphology characteristic of malignant cells were counted. The mean number of signals per cell was calculated by totaling the number of signals from each cell and dividing by the number of cells counted. Mean ERBB2 and mapping probe signals per cell were divided by the mean CEP17 signals per cell to pro- 
vide the ratio of ERBB2-to-chromosome 17 signals and mapping probe-to-chromosome 17 signals. A lower ratio cutoff of 0.75 and an upper ratio cutoff of 2.00 were selected for deletion and amplification, respectively [30].

\section{Immunohistochemistry}

In preparation for antibody staining, paraffin sections (5 microns, freshly cut) were deparaffinized and rehydrated using standard technique. A microwave antigen retrieval method was then carried out in citrate buffer. The tissue was stained using a Ventana ES Histo-stainer (Ventana Medical Systems, Tucson, AZ), using supplied diaminobenzidine and avidin-biotin conjugate immunoperoxidase chemistry. Sections were stained for TOP2A with the JH2.7 monoclonal antibody from Lab Vision Corp. (Fremont, CA) at a dilution of 1:100 and MIB1 with the Ki-S5 antibody (Dakcytomation, Carpeneria, CA), dilution 1:50. A single block from the pre-therapy biopsy was selected for analysis for each patient on the basis of having the greatest area of well-preserved tumor. Immunostaining frequency of all tumor cells on each slide was scored subjectively on a scale of 0 to 4 (actual cell counting was not performed) without knowledge of clinical patient data, as previously described [49]. Less than $1 \%$ positive tumor cells were scored as $0,1-10 \%$ as $1,11-35 \%$ rated $2,36-70 \%$ rated 3 and over $70 \%$ rated 4 on the scale. Tumor cell staining intensity was also scored on a scale of 0 to 4 , but was found to be so closely related to frequency that it was not further considered in this study. Only nuclear staining was considered for TOP2A.

\section{Statistical analysis}

Fisher's exact tests and Chi-square tests were used to measure the significance of the association between pairs of categorical variables such as those between the amplicon class, patient descriptors, molecular variables and the clinical outcome of evidence of disease. Permutation based exact p-value were used for these tests since they are more appropriate for small sample size. Specimens were divided into 4 categories based on the FISH data as explained below. Immunohistochemical expression was divided into three categories: overexpressed (frequency $3+$ and $4+$ ), expressed (frequency $1+$ and $2+$ ) and undetected (frequency 0).

Time to recurrence and overall survival were measured as months from the start of treatment to the time of tumor recurrence, death or last follow-up. Survival curves were estimated by the Kaplan-Meier method and are compared by the log-rank test. Due to the relatively small sample sizes, exact permutation based $\mathrm{p}$-values, available in the $\mathrm{R}$ statistical software, are reported for the log-rank test. Age adjusted time to recurrence and time to survival are analyzed using the Cox proportional hazards regression. SAS version 9.0 and the $\mathrm{R}$ statistical software were used in the data analysis. All reported p-values are two-sided.

\section{List of Abbreviations}

BC: Breast carcinoma; TOP2A: Topoisomerase II alpha; FISH: Fluorescence In-Situ Hybridization; NED: No evidence of disease; AWD: Alive with recurrent breast cancer; DOD: Died of breast cancer; DNED: Dead with no evidence of disease at least 24 months after diagnosis; ER: Estrogen receptor; PR: Progesterone receptor; IHC: Immunohistochemistry.

\section{Competing interests}

Larry E. Morrison and Kris Jacobson are employees of Abbott Molecular Inc. John S. Coon has received research funding from the same company.

\section{Authors' contributions}

LU helped to plan the study and wrote the manuscript. BT and RR gathered and interpreted clinical data. LM and KJ performed the FISH analysis and interpreted the data. AZ and SB performed statistical analysis and helped to format and interpret the data. JC helped to plan the study and contributed significantly to writing the manuscript.

\section{Acknowledgements}

We thank Susan S. Jewell, PhD for her valuable assistance in preparing the Diagram with the location of FISH probes and selected genes on chromosome 17.

\section{References}

I. Slamon DJ, Godolphin W, Jones LA, Holt JA, Wong SG, Keith DE, Levin WJ, Stuart SG, Udove J, Ullrich A: Studies of the HER-2/neu proto-oncogene in human breast and ovarian cancer. Science 1989, 244:707.

2. Revillion F, Bonneterre J, Peyrat JP: ERBB2 oncogene in human breast cancer and its clinical significance. Eur J Cancer 1998, 34:79I-808.

3. Dickson RB, Pestell RG, Lippman ME: Cancer of the Breast. In Cancer Principles \& Practice of Oncology Volume I. 7th edition. Edited by: DeVita VT, Hellman S, Rosenberg SA. Philadelphia: Lippincott, Williams \& Wilkins; 2005: 1412.

4. Berns EM, Foekens JA, Van Staveren IL, Van Putten WL, de Koning $\mathrm{HY}$, Portengen H, Klijn JG: Oncogene amplification and prognosis in breast cancer: relationship with systemic treatment. Gene 1995, 159:1 I-8.

5. Cobleigh MA, Vogel CL, Tripathy D, Robert NJ, Scholl S, Fehrenbacher L, Wolter JM, Paton V, Shak S, Lieberman G, Slamon DJ: Multinational study of the efficacy and safety of humanized antiHER2 monoclonal antibody in women who have HER2-overexpressing metastatic breast cancer that has progressed after chemotherapy for metastatic disease. J Clin Oncol 1999, I 7:2639-48.

6. Slamon DJ, Leyland-Jones B, Shak S, Fuchs H, Paton V, Bajamonde A, Fleming T, Eiermann W, Wolter J, Pegram M, Baselga J, Norton L: Use of chemotherapy plus a monoclonal antibody against HER2 for metastatic breast cancer that overexpresses HER2. N Engl J Med 200I, 344:783.

7. Piccart-Gebhart MJ, Procter M, Leyland-Jones B, Goldhirsch A, Untch M, Smith I, Gianni L, Baselga J, Bell R, Jackisch C, Cameron D, Dowsett M, Barrios CH, Steger G, Huang CS, Andersson M, Inbar M, Lichinitser M, Lang I, Nitz U, Iwata H, Thomssen C, Lohrisch C, Suter TM, Ruschoff J, Suto T, Greatorex V, Ward C, Straehle C, McFadden E, Dolci MS, Gelber RD, Herceptin Adjuvant IHERA. Trial Study 
Team: Trastuzumab after adjuvant chemotherapy in HER2positive breast cancer. N Engl J Med 2005, 353:1659-72.

8. Kauraniemi P, Kuukasjarvi T, Sauter G, Kallioniemi A: Amplification of a 280-kilbase core region at the ERBB2 locus leads to activation of two hypothetical proteins in breast cancer. $\mathrm{Am} J$ Pathol 2003, 163(5): 1979-1984.

9. Di Leo A, Gancberg D, Larismont D, Tanner M, Jarvinen T, Rouas G, Dolci S, Leroy JY, Paesmans M, Isola J, Piccart MJ: HER-2 amplifications and topoisomerase II $\alpha$ gene aberrations with predictive markers in node-positive breast cancer patients randomized treated with an anthracycline-based therapy or with cyclophosphamide, methotrexate and 5-fluoroouracil. Clin Cancer Res 2002, 8: I 107-16.

10. Di Leo A, Isola J: Topoisomerase II $\alpha$ as a marker predicting the efficacy of anthracyclines in breast cancer: are we at the end of the beginning. Clin Breast Cancer 2003, 4:179-86.

II. Durbecq V, Paesmans M, Cardoso F, Desmedt C, DiLeo A, Chan S, Friedrichs K, Pinter T, Van Belle S, Murray E, Bodrogi I, Walpole E, Lesperance B, Korec S, Crown J, Simmonds P, Perren TJ, Leroy JY, Rouas G, Sotiriou C, Piccart M, Larsimont D: Topoisomerase-Il $\alpha$ expression as a predictive marker in a population of advanced breast cancer patients randomly treated either with single-agent doxorubicin or single-agent docetaxel. Mol Cancer Ther 2004, 3: I207-I4.

12. Murthy SK, Magliocco AM, Demetrick DJ: Copy number analysis of c-erb-B2 (HER-2/neu) and topoisomerase Ilalpha genes in breast carcinoma by quantitative real-time polymerase chain reaction using hybridization probes and fluorescence in situ hybridization. Arch Pathol Lab Med 2005, 129:39-46.

13. Olsen KE, Knudsen H, Rasmussen BB, Balslev E, Knoop A, Ejlertsen B, Knoop A, Ejlertsen B, Nielsen KV, Schonau A, Overgaard J, Danish Breast Cancer Co-operative Group: Amplification of HER2 and TOP2A and deletion of TOP2A genes in breast cancer investigated by new FISH probes. Acta Oncol 2004, 43:35-42.

14. Jarvinen TA, Liu ET: HER-2/neu and topoisomerase Ilalpha in breast cancer. Breast Cancer Res Treat 2003, 78:299-3II

15. Depowski PL, Rosenthal SI, Brien TP, Stylos S, Johnson RL, Ross JS: Topoisomerase II $\alpha$ expression in breast cancer: correlation with outcome variables. Modern Pathology 2000, 13:542-47.

16. Fritz P, Cabrera CM, Dippon J, Gerteis A, Simon W, Aulitzky WE, Kuip $H$ van der: C-erbB2 and topoisomerase Ilalpha protein expression independently predict poor survival in primary human breast cancer: a retrospective study. Breast Cancer Res 2005, 7:374-84.

17. Takimoto $\mathrm{CH}$ : Topoisomerase interactive agents. In Cancer Principles \& Practice of Oncology Volume I. 7th edition. Edited by: DeVita VT, Hellman S, Rosenberg SA. Philadelphia: Lippincott, Williams \& Wilkins; 2005:375-390.

18. Arpino G, Ciocca DR, Weiss H, Allred DC, Daguerre P, Vargas-Roig L, Leuzzi M, Gago F, Elledge R, Mohsin SK: Predictive value of apoptosis, proliferation, HER-2, and topoisomerase Ilalpha for anthracycline, chemotherapy in locally advanced breast cancer. Breast Cancer Res Treat 2005, 92:69-75.

19. Cardoso F, Durbecq V, Larsomont D, Paesmans M, Leroy YJ, Rouas G, Sotiriou C, Renard N, Richard V, Piccart MJ, Di Leo A: Correlation between complete response to anthracycline-based chemotherapy and topoisomerase II $\alpha$ gene amplification and protein overexpression in locally advanced/metastatic breast cancer. Int J Oncol 2004, 24:20I-9.

20. Colozza M, Sidoni A, Mosconi AM, Cavaliere A, Bisagni G, Gori S, De Angelis V, Frassoldati A, Cherubini R, Bian AR, Rodino C, Mazzocchi B, Mihailova Z, Bucciarelli E, Tonato M: Italian Oncology Group for Clinical Research. HER2 overexpression as a predictive marker in a randomized trial comparing adjuvant cyclophosphamide/methotrexate/5-fluorouracil with epirubicin in patients with stage I/II breast cancer: long-term results. Clin Breast Cancer 2005, 6:253-9.

21. Dressler LG, Berry DA, Broadwater G, Gowan D, Cox K, Griffin S, Miller A, Tse J, Novotny D, Persons DL, Barcos M, Henderson IC, Liu ET, Thor A, Budman D, Muss H, Norton L, Hayes DF: Comparison of HER2 status by fluorescence in situ hybridization and immunohistochemistry to predict benefit from dose escalation of adjuvant doxorubicin-based therapy in node-positive breast cancer patients. J Clin Oncol 2005, 23:4287-97.

22. Moliterni A, Menard S, Valagussa P, Biganzoli E, Boracchi P, Balsari A, Casalini P, Tomasic G, Marubini E, Pilotti S, Bonadonna G: HER2 overexpression and doxorubicin in adjuvant chemotherapy for resectable breast cancer. J Clin Oncol 2003, 21 :458-62.

23. Piccart M, Lohrisch C, DiLeo A, Larsimont $D$ : The predictive value of HER2 in breast cancer. Oncology 200I, 2:73-82.

24. Park K, Kim J, Lim S, Han S: Topoisomerase II $\alpha$ (topoll) and HER2 amplification in breast cancers and response to preoperative doxorubicin chemotherapy. Eur I Cancer 2003, 39:63I-34.

25. Coon JS, Marcus E, Gupta-Burt S, Seelig S, Jacobson K, Chen S, Renta V, Fronda G, Preisler HD: Amplification and overexpression of topoisomerase II $\alpha$ predict response to anthracycline-based therapy in locally advanced breast cancer. Clinical Cancer Research 2002, 8: I06I-7.

26. Arriola E, Rodriguez-Pinilla SM, Lambros MB, Jones RL, James M, Savage K, Smith IE, Dowsett M, Reis-Filho JS: Topoisomerase II alpha amplification may predict benefit from adjuvant anthracyclines in HER2 positive early breast cancer. Breast Cancer Res Treat 2007, 106(2): |8|-9.

27. Schindlbeck C, Janni W, Shabani N, Kornmeier A, Rack B, Rjosk D, Gerber B, Braun S, Sommer H, Friese K: Isolated tumor cells in the bone marrow (ITC-BM) of breast cancer patients before and after anthracyclin based therapy: influenced by the HER2- and Topoisomerase Ilalpha-status of the primary tumor? J Cancer Res Clin Oncol 2005, I 3 I:539-546.

28. Burgess DJ, Doles J, Zender L, Xue W, Ma B, McCombie WR, Hannon G], Lowe SW, Hemann MT: Topoisomerase levels determine chemotherapy response in vitro and in vivo. Proc Natl Acad Sci USA 2008, I 05(26):9053-8.

29. Hicks DG, Yoder BJ, Pettay J, Swain E, Tarr S, Hartke M, Skacel M, Crowe JP, Budd GT, Tubbs RR: The incidence of topoisomerase II-alpha genomic alterations in adenocarcinoma of the breast and their relationship to human epidermal growth factor receptor- 2 gene amplification: a fluorescence in situ hybridization study. Hum Pathol 2005, 36:348-56.

30. Jacobson KK, Morrison LE, Henderson BT, Blondin BA, Wilber KA, Legtor MS, O'Hare A, Van Stedum SC, Proffitt JH, Seelig SA, Coon JS: Gene copy mapping of the ERBB2/TOP2A region in breast cancer. Genes Chromosomes Cancer 2004, 40:19-31.

31. Jarvinen TA, Tanner M, Barlund M, Borg A, Isola J: Characterization of topoisomerase II $\alpha$ gene amplification and deletion in breast cancer. Genes, Chromosomes and Cancer 1999, 26:142-50.

32. Kauraniemi P, Barlund M, Monni O, Kallioniemi A: New amplified and highly expressed genes discovered in the ERBB2 amplicon in breast cancer by cDNA microarrays. Cancer Research 200I, 6 I:8235-40.

33. MacGrogan G, Rudolph P, Mascarel IDI, Mauriac L, Durand M, Avril A, Dilhuydy JM, Robert J, Mathoulin-Pelissier S, Picot V, Floquet A, Sierankowski G, Coindre JM: DNA topoisomerase Il $\alpha$ expression and the response to primary chemotherapy in breast cancer. Br J Cancer 2003, 89:666-7I.

34. Martin-Richard M, Munoz M, Albanell J, Colomo L, Bellet M, Rey MJ Tabernero J, Alonso C, Cardesa A, Gascon P, Fernandez PL: Serial topoisomerase II expression in primary breast cancer and response to neoadjuvant anthracycline-based chemotherapy. Oncology 2004, 66:388-94.

35. Petit T, Wilt M, Velten M, Millon R, Rodier JF, Borel C, Mors R, Haegele P, Eber M, Ghnassia JP: Comparative value of tumor grade, hormonal receptors, Ki-67, HER-2 and topoisomerase Il $\alpha$ status as predictive markers breast cancer patients treated with neoadjuvant anthracycline-based chemotherapy. Eur J Cancer 2004, 40:205-II.

36. Rudolph P, MacGrogan G, Bonichon F, Frahm SO, de Mascarel I, Trojani M, Durand M, Avril A, Coindre JM, Parwaresch R: Prognostic significance of $\mathrm{Ki}-67$ and topoisomerase II $\alpha$ expression in infiltrating ductal carcinoma of the breast. a multivariate analysis of 863 cases. Breast Cancer Research 1999, 55:6I-7I.

37. Jarvinen TA, Tanner M, Rantanen V, Barlund M, Borg A, Grenman S, Isola J: Amplification and deletion of topoisomerase II $\alpha$ associate with erb-2 amplification and affect sensitivity to topoisomerase II inhibitor doxorubicin in breast cancer. Am J Pathol 2000, I 56(3):839-47.

38. Knoop AS, Knudsen H, Balslev E, Rasmussen BB, Overgaard J, Nielsen KV, Schonau A, Gunnarsdottir K, Olsen KE, Mouridsen H, Ejlertsen B, Danish Breast Cancer Cooperative Group: Retrospective analysis of topoisomerase Ila amplifications and deletions as predictive markers in primary breast cancer patients randomly 
assigned to cyclophosphamide, methotrexate, and fluorouracil or cyclophosphamide, epirubicin, and fluorouracil: Danish Breast Cancer Cooperative Group. J Clin Oncol 2005, 23:7483-90.

39. Tanner $\mathrm{M}$, Isola J, Wiklund $\mathrm{T}$, Erikstein $\mathrm{B}$, Kellokumpu-Lehtinen $\mathrm{P}$, Malmstrom P, Wilking N, Nilsson J, Bergh J: Topoisomerase Ilalpha gene amplification predicts favorable treatment response to tailored and dose-escalated anthracycline-based adjuvant chemotherapy in HER-2/neu-amplified breast cancer: Scandinavian Breast Group Trial 9401 . J Clin Oncol 2006, 24:2428-2436.

40. Jarvinen TA, Liu ET: Topoisomerase Il $\alpha$ gene (TOP2A) amplification and deletion in cancer - more common than anticipated. Cytopathology 2003, 14:314-9.

4I. Park K, Han S, Gwak GH, Kim HJ, Kim J, Kim KM: Topoisomerase II-alpha gene deletion is not frequent as its amplification in breast cancer. Breast Cancer Res Treat 2006, 98:337-42.

42. Nielsen KV, Ejlertsen B, Moller S, Jorgensen JT, Knoop A, Knudsen H, Mouridsen HT: The value of TOP2A gene copy number variation as a biomarker in breast cancer: Update of DBCG trial 89D. Acta Oncol 2008, 47(4):725-734.

43. Carlson RW, Brown E, Burstein HJ, Gradishar WJ, Hudis Ca, Loprinzi C. Mamounas EP, Perez EA, Pritchard K, Ravdin P, Recht A, Somio G, Theriault RL, Winer EP, Wolff AC, National Comprehensive Cancer Network: NCCN Task Force Report: adjuvant therapy for breast cancer. I Natl Compr Canc Netw 2006, 4(Suppl I):SI-26.

44. Romond EH, Perez EA, Bryant J, Suman VJ, Geyer CE Jr, Davidson NE, Tan-Chiu E, Martino S, Paik S, Kaufman PA, Swain SM, Pisansky TM, Fehrenbacher L, Kutteh LA, Vogel VG, Visscher DW, Yothers G, Jenkins RB, Brown AM, Dakhil SR, Mamounas EP, Lingle WL, Kelin PM, Ingle JN, Wolmark N: Trastuzumab plus adjuvant chemotherapy for operable HER2-positive breast cancer. $N$ Engl J Med 2005, 353:1673-84.

45. Press MF, Bernstein L, Sauter G, Zhou JY, Eiermann W, Pienkowski T, Crown J, Robert N, Bee V, Taupin H, Villalobos I, Seelig S, Pegram M, Slamon DJ: Topoisomerase II-alpha gene amplification as a predictor of responsiveness to anthracycline-containing chemotherapy in the Cancer International Research Group 006 clinical trial of trastuzumab (herceptin) in the adjuvant setting [abstract]. 28th Annual San Antonio Breast Cancer Symposium 2005:A1045.

46. Morrison LE, Jewell SS, Usha L, Blondin BA, Rao RD, Tabesh B, Kemper M, Batus M, Coon JS: Effects of ERBB2 amplicon size and genomic alterations of chromosomes $I, 3$, and 10 on patient response to trastuzumab in metastatic breast cancer. Genes, Chromosomes and Cancer 2007, 46:397-405.

47. Kim MS, Blake M, Baek JH, Kohlhagen G, Pommier Y, Carrier F: Inhibition of histone deacetylase increases cytotoxicity to anticancer drugs targeting DNA. Cancer Res 2003, 63(2I):729I-7300.

48. Marchion DC, Bicaku E, Daud AL, Richon V, Sullivan DM, Munster PN: Sequence-specific potentiation of topoisomerase II inhibitors by histone deacetylase inhibitor suberoylanilide hydroxamic acid. J Cell Biochem 2004, 92:223-37.

49. Venkatesan TK, Kuropkat C, Caldarelli DD, Panje WR, Hutchinson JC, Chen S, Coon JS: Prognostic significance of p27 expression in carcinoma of the oral cavity and oropharynx. Laryngoscope 1999, 109:1329-1333.
Publish with Bio Med Central and every scientist can read your work free of charge

"BioMed Central will be the most significant development for disseminating the results of biomedical research in our lifetime. "

Sir Paul Nurse, Cancer Research UK

Your research papers will be:

- available free of charge to the entire biomedical community

- peer reviewed and published immediately upon acceptance

- cited in PubMed and archived on PubMed Central

- yours - you keep the copyright
BioMedcentral 